\title{
Bullous Pemphigoid an Autoimmune Skin Disease: A Case Report
}

\author{
Maheshwari. ${ }^{1 *}$, Tasneem Abdul Gafoor ${ }^{1}$, Ajeena Anto ${ }^{1}$, Syam Prakash KR ${ }^{1}$, Shahina KP ${ }^{2}$, Manju Mohan ${ }^{3}$ \\ ${ }^{1}$ Pharm D Interns, Department of Pharmacy Practice, Nandha College of Pharmacy, Erode, Tamil Nadu, India. \\ ${ }^{2}$ Clinical Pharmacist, Department of Clinical Pharmacy, IQRAA International Hospital and Research Centre, Calicut, India. \\ ${ }^{3}$ Pharmacist, Department of Pharmacology, IQRAA International Hospital and Research Centre, Calicut, India.
}

*Corresponding author's E-mail: maheshwarivengat@gmail.com

Received: 12-08-2020; Revised: 24-10-2020; Accepted: 30-10-2020; Published on: 15-11-2020.

\section{ABSTRACT}

Bullous pemphigoid (BP) is a subepidermal blistering-related autoimmune and inflammatory skin disease. It is present most often in the elderly and is diagnosed on the basis of clinical, histological and immunological criteria. Clinically, it presents with diffuse eczematous, pruritic, urticaria-like lesions, usually filled with clear fluid with the later emergence of tense bullae or blistering lesions. In our case. A 42-year-old female patient have bullous lesions all over the body for past 1 month. The main diagnosis was bullous pemphigoid in a recently diagnosed type 2 diabetic mellitus. Patient was placed on corticosteroids as well as immunosuppressive agents and diabetes was managed with subcutaneous insulin and oral hypoglycemics. By way of skin biopsy and histology, Bullous Pemphigoid (BP) may be clinically diagnosed with a high index of suspicion.

Keywords: Bullous pemphigoid, subepidermal, eczematous, Pruritic, Utricaria, bullae, immunosuppressive agents.

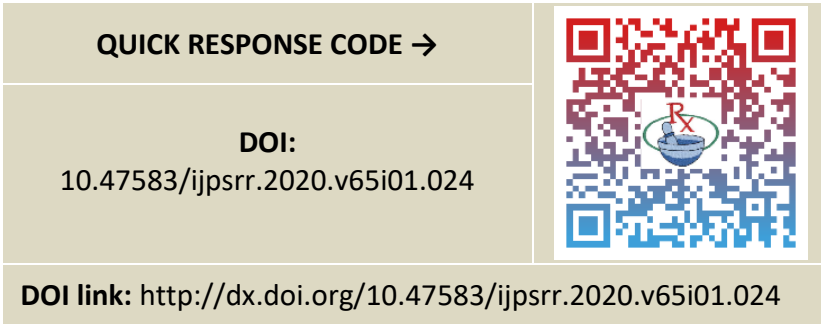

\section{INTRODUCTION}

ullous pemphigoid (BP) is the most common type of blistering disorders ${ }^{1}$. It is most commonly found in the elderly ${ }^{1,2}$ and is mainly diagnosed based on clinical, histological, and immunological criteria [2-4]. The incidence is between 0.2 and 3 per 100,000 person years. In India, Pemphigus vulgaris (PV) is more common than BP. During the fifth to seventh decade of life, it affects older people, with an average starting age of 65 years. $^{3}$

In general, the immune system creates antibodies to combat the bacteria, viruses or other potentially harmful foreign substances. The body may produce an antibody to a specific tissue in your body for reasons that are not obvious. The immune system produces antibodies to the fibres in the bullous pemphigoid that connect the outer layer of the skin (epidermis) and the next layer of the skin (dermis). These antibodies cause inflammation that causes bullous pemphigoid blisters and pruritus. Corticosteroid therapy as well as immunosuppressive agents are the main stay of treatment.

\section{CASE REPORT}

A 42 year old female patient came to the hospital with the complaints of small red lesions and severe pruritis. Following days it got worsened, bullous lesions appeared all over the body. Initially presented with small red lesions followed by increase in size and was exfoliated. The patient was admitted under dermatology department. Patient had discrete grouped lesions on chest, right wrist, left forearm, right flank and back. On general examination patient was conscious and oriented. BP was $120 / 80 \mathrm{mmHg}$, pulse rate was normal. On laboratory investigation, patient blood glucose was high $183 \mathrm{mg} / \mathrm{dl}$ and was diagnosed as newly diagnosed with $\mathrm{DM}$. $\mathrm{Hb}$ was low $9.5 \mathrm{gm} / \mathrm{dl}, \mathrm{WBC} 13,000$ cells/cumm. Urine culture showed the presence of staphylococcus growth. CRP was high $111.00 \mathrm{mg} / \mathrm{l}$. Peripheral smear examination indicated microcytic hypochromic anemia, suggestive for iron deficiency anaemia, moderate eosinophillia $(30 \%)$, and mild thrombocytopenia.

On histopathology examination, the IgG and C3-2 + linear along the basement membrane. IgA and IgM were negative that confirmed the final diagnosis of Bullous Phemphigoid.

After 2 days, the lesions size got increased and there was oozing from the lesions. The patient had complaints of itching all over the body. Initially patient was managed with symptomatic treatment. The patient was started on Topical cream CLOBETASOL PROPIONATE+ NEOMYCIN SULPHATE once daily every night. For itching, T.PROMETHAZINE $10 \mathrm{mg}$ BD was given. since the patient condition got worsened, he was started on INJ. DEXAMETHASONE 40mg IV BD for 4 days and INJ. CLINDAMYCIN+ DISODIUM EDETATE. Following 3 days itching got reduced. The patient was given INJ. METHYL PREDNISOLONE 250mg IV $\mathrm{w}$ along with INJ. RITUXIMAB $24 \mathrm{ml} / \mathrm{hr}$ intradermal as first dose, further 4 doses of rituximab was given. The patient was symptomatically better after the completion of first cycle and hence got 
discharged. The patient was advised to complete the following 5 cycle as per the protocol.

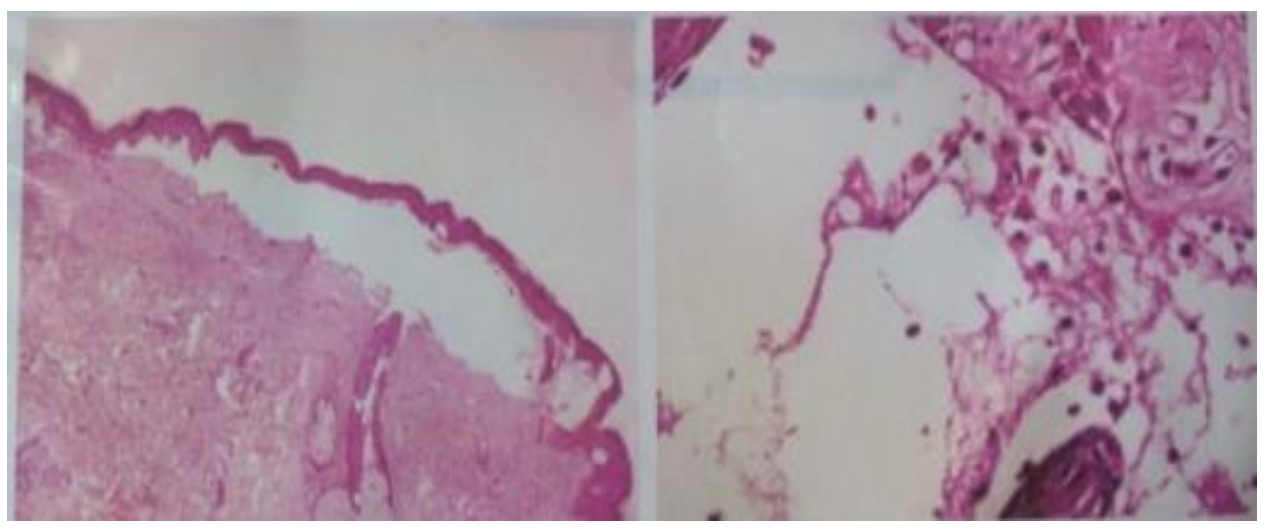

Figure 1: Histopathology Examination

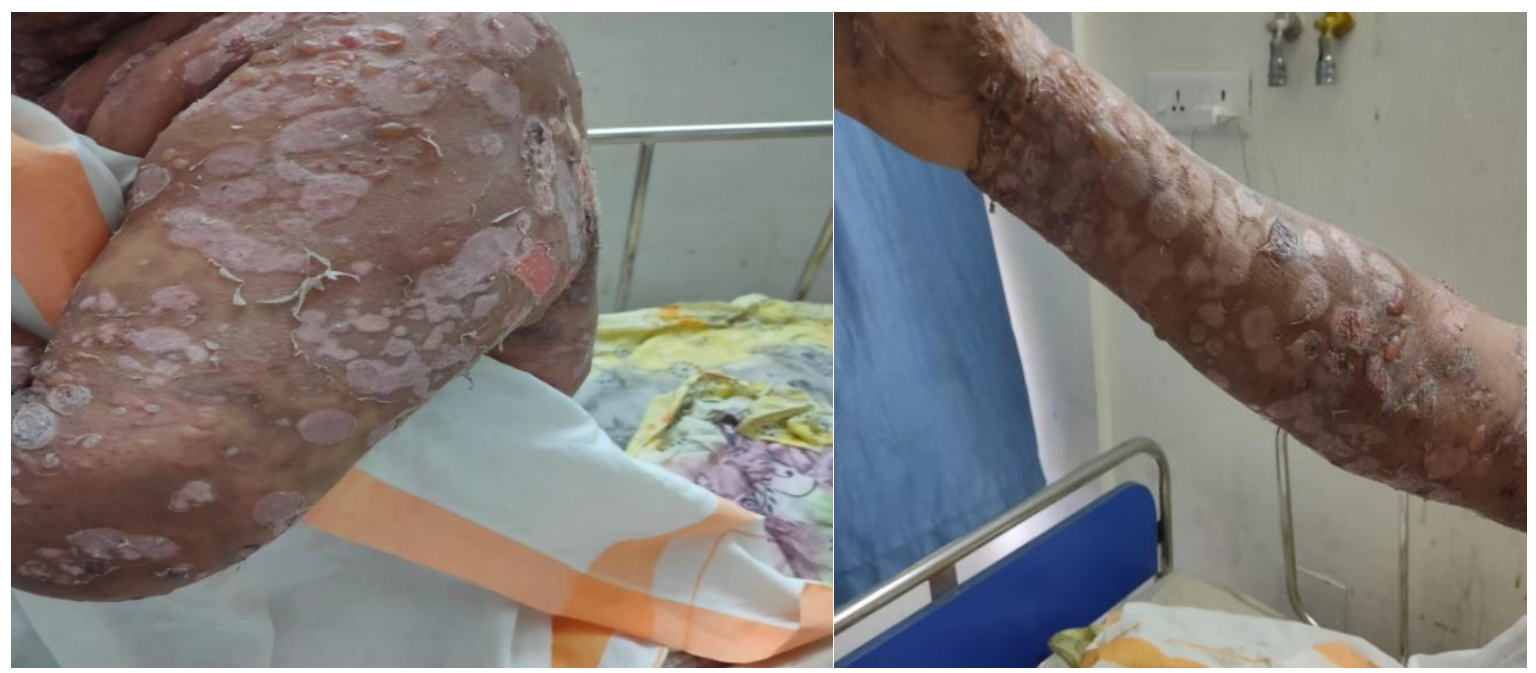

Figure 2: Bullous Lesion

\section{DISCUSSION}

$\mathrm{BP}$ is an autoimmune disorder characterised by the presence of IgG antibodies directed against the structural components of the keratinocytic hemidesmosomal proteins BP180 and BP230 ${ }^{1,3}$

Antibody levels directly correlates with disease activity ${ }^{2,3}$. Focal separation of the epidermis and dermis results intense sub epidermal blister formation.

Initially, BP is characterised by the development of diffuse eczematous, pruritic, urticaria-like lesions, typically filled with clear fluid with the later appearance of tense bullae or blistering lesions. Lesions are primarily found in the trunk, the extremities flexor compartments and the axillary region ${ }^{3}$. The blisters generally heal without scarring, and their appearance follows a waxing and waning course ${ }^{2,3}$.

On admission, blood glucose and glycated haemoglobin ( $\mathrm{HbA1c}$ ) was elevated and the patient was diagnosed with type 2 diabetes mellitus despite not having symptoms. Diabetes mellitus is itself associated with Bullous pemphigoid without any prior administration of corticosteroid which can predispose to Diabetic mellitus ${ }^{4}$ The mechanisms involved are increased skin fragility due to hyperglycemia and the formation of auto antibodies by glycosylation of dermal proteins. ${ }^{5}$ It can be argued that Type 1 diabetes is more closely related to autoantibodies and autoimmune disease; but, since it developed in old age, Type $2 \mathrm{DM}$ is more likely to be in this patient.

IgG auto antibodies in patients with bullous pemphigoid bind to the skin basement membrane. Complement and inflammatory mediators are activated by the binding of antibodies in the basement membrane. By attracting the inflammatory cells to the basement membrane, activation of the complement system is believed to play a critical role. These inflammatory cells are postulated to release proteases, which degrade hemidesmosomal proteins and leads to blister formation. As shown by histopathological examination, eosinophils are usually present in the blisters of patients, although their existence is not an absolute diagnostic criterion.

Proper treatments of bullous pemphigoid depends upon the disease severity. Three categories of drugs are the main stay of the treatment. ${ }^{2,4}$ The first category is antiinflammatory drugs, such as topical steroids, sulfonamides, and antibiotics with anti-inflammatory properties like tetracycline. For severe cases, systemic steroids along with 
immunosuppressives may be needed to manage the disease. Another drug class consists of those that decrease the production of antibodies such as systemic steroids such as azathioprine, methotrexate, mycophenolate, cyclosporin, and rituximab. Lastly, medications that increase the elimination of abnormal antibodies like plasmapheresis and intravenous immunoglobulin (IVIG) can be done. If the disease is difficult to manage, an anti-CD20 antibody (rituximab), which is relatively specific in targeting the antibody-producing B cells may be considered (med).

\section{CONCLUSION}

$\mathrm{BP}$ is not a common disease and can occur in poor settings lacking the specific diagnostic tool such as immunofluorescence, however diagnosis can be also made based on clinical presentation, physical examination and skin biopsy and histology with light microscopy. Adverse reactions can occur during the treatment period. Treatment is usually multidisciplinary. This case report aims to increase awareness and highlight differing treatments of $\mathrm{BP}$, as well as to advocate referral to a dermatologist, given its potential severity.

\section{REFERENCES}

1. Lo Schiavo A, Ruocco E, Brancaccio G, Caccavale S, Ruocco $\mathrm{V}$, Wolf R: Bullous pemphigoid etiology, pathogenesis, and inducing factors: facts and controversies. Clin Dermatol. 31, 2013, 391-399.

2. Fuertes de Vega I, Iranzo-Fernandez P, Mascaro-Galy JM: Bullous pemphigoid clinical practice guidelines. Actas Dermosifiliogr. 105, 2014, 328-346

3. Khandpur S, Verma P. Bullous pemphigoid. Indian J Dermatol Venereol Leprol, 77, 2011, 450-5

4. Cozzani E, Gasparini G, Burlando M, Drago F, Parodi A: Atypical presentations of bullous pemphigoid: clinical and immunopathological aspects. Autoimmun Rev. 14, 2015, 438-445.

5. Ludwig RJ, Kalies J, Kohl J, Zillikens D, Schmidt E: Emerging treatments for pemphigoid diseases. Trends Mol Med. 19, 2013, 501-512.

6. Cozzani E, Gasparini G, Burlando M, Drago F, Parodi A. Atypical presentations of bullous pemphigoid: Clinical and immunopathological aspects. Autoimmunity Reviews. 14(5), 2015 May 1, 438-45.

Source of Support: None declared.

Conflict of Interest: None declared.

For any question relates to this article, please reach us at: editor@globalresearchonline.net

New manuscripts for publication can be submitted at: submit@globalresearchonline.net and submit_ijpsrr@rediffmail.com 